\title{
CLEAN AIR POLICY IN EUROPEAN MARINE PORTS
}

\author{
Dorota KSIĄŻKIEWICZ \\ University of Gdańsk, Faculty of Economics, Transportation Policy Chair; d.ksiazkiewicz@ug.edu,pl, \\ ORCID: 0000-0002-8751-819x
}

Purpose: The goal of the article is to analyse the tolls and measures of emission control in port areas and to build a Clean Air Policy action model for marine and inland shipping ports, which would constitute a universal framework for building and conducting the Clean Air Policy in port areas.

Design/methodology/approach: The research is based on data from reports and studies concerning the impact of port-generated emissions on air quality in the port areas. Legal framework for Air Quality Control in Marine Shipping is analysed. Examples of actions and policy measures in European ports are listed.

Findings: Port areas and the processes inside them generate airborne pollution from various sources with vehicles, ships and port machinery being the main ones. Air pollution is one of the factors influencing ports' natural environment and a cause of many health hazards to local residents. Ports are usually located in urban areas or close to city centres, and thus the environmental impact of air pollution is significant. Some ports have decided to voluntarily implement programs directed to measure and reduce the level of port emissions, but there is little business interest in general for the ports to reduce emissions and energy consumption. Numerous workshops aimed to improve air quality in ports in Europe were held in port cities, resulting in best practices and projects aimed at reducing port emissions. However there is still no standard activity framework for Clean Air Policy in European ports. Action model presented in the article may be used for building and conducting the Clean Air Policy in port areas.

Research limitations/implications: Action model presented in the article constitutes a universal framework for building and conducting the Clean Air Policy in port areas. However the model constitutes a universal base, and in any case the specificity of the port must be taken into account, e.g. geographical factors, size and specialization of the port, type of machinery and equipment used, other pollution sources, proximity to urban areas.

Practical implications: The results may be a factor to influence ports' Corporate Social Responsibility measures, directed to improve the quality of life in the ports' neighbouring areas. Social implications: It is important to address the problem of port-generated air pollution for urban zones to limit its influence on quality of life in the neighbouring areas.

Originality/value: A universal approach to creating Clean Air Policy action model for marine ports is presented.

Keywords: clean air policy, air pollution, emissions, marine ports, air quality.

Category of the paper: Research paper, general review. 


\section{Introduction}

Development of port areas and growing cargo traffic in marine ports across Europe result in growing environmental pressure in these areas. Air pollution is one of the factors influencing ports' natural environment and a cause of many health hazards to local residents. Ports are usually located in urban areas or close to city centres, and thus the environmental impact of air pollution is significant. Numerous workshops aimed to improve air quality in ports in Europe were held in port cities (NABU, 2015) presenting best practices and projects aimed at reducing port emissions. However there is no clear vision on how to support clean shipping and port operations.

Air pollution in ports is caused by numerous factors, the majority of which are related to the use of port equipment and machinery, mostly propelled with diesel engines. Marine vessels coming to a port for reloading operations remain another source of air pollution. Some ports have decided to voluntarily implement programs directed to measure and reduce the level of port emissions, but there is little business interest for the ports to reduce emissions and energy consumption. The impact of air pollution in port areas on their surroundings is difficult to measure, as ports are usually located in windy coastal areas and therefore the influence is often not directly measurable and not investigated. Furthermore, as most ports are located in urban areas with industrial zones usually surrounding port borderline, air quality inside port area may also be strongly affected by outside emissions. However, main pollutants emission together with energy consumption in port areas can be calculated to identify carbon footprint created by ports.

\section{Legal framework for Air Quality Control in Marine Shipping}

Air Quality remains the main environmental concern for many European ports. As ESPO Environmental Report (ESPO, 2018) shows, air quality has been a top environmental priority of the European ports' managing bodies since 2013. The second priority is also emissionrelated: it is energy consumption. Marine ports are areas where various industrial and transport processes take place. There are three main sources of pollution in port areas:

- shipping activity in port area,

- port operations and infrastructure,

- intermodal transport means entering port area.

Each of them involves processes that imply the use of specialized infrastructure and machinery. An extensive infrastructure is needed to handle large quantities of different types of goods. The basic parameter characterizing the port infrastructure is the land area of the port, 
i.e. the land intended exclusively for port operations. This area is transformed into industrial zone and therefore it is deprived of its natural character which subsequently strongly affects the surrounding ecosystems. The area occupied by an average seaport is large, e. g. the port of Gdańsk occupies a land area of almost 680 ha (1679 acres) with a total quay area of about $37,5 \mathrm{~km}$. Typical port infrastructure consists of warehouses, storage yards, port operation offices, cargo handling areas, inner transport routes, port logistics equipment, passenger facilities, quays and piers, parking space, infrastructure for transshipment with other means of transport (rail, road or inland shipping) to facilitate convergence between land transport and maritime systems. Buildings and other amenities cause the energy consumption due to the need for lighting, office and warehouse equipment, communication systems and air conditioning systems.

Together with the infrastructure, there comes a need for various vehicles to move cargo within the port area. These typically include diesel trucks, locomotives, cargo handling equipment, harbour craft and vessels calling the port for reloading operations. Some ports opt for the use of eco-efficient equipment that cuts emissions, for example in Kalmar an extensive range of electrically powered equipment, including rail-mounted and rubber tyred gantry cranes, automated guided vehicles, shuttle and straddle carriers and terminal tractors is used. They produce little emissions as well as significantly reduce noise level.

Rising airborne emissions and noise levels make the ports and shipping lines face increasingly strict regulations. According to IMO regulations, until 31 December 2019, for ships operating outside Emission Control Areas, the limit for sulphur content of ships' fuel oil is $3.50 \% \mathrm{~m} / \mathrm{m}$ (mass by mass). The $0.50 \% \mathrm{~m} / \mathrm{m}$ limit will apply starting from 1 January 2020 . Under the new sulphur limit, ships will have to use fuel oil on board with a sulphur content of no more than $0.50 \% \mathrm{~m} / \mathrm{m}$, against the current limit of $3.50 \%$, which has been applicable since 1 January 2012. The requirement includes fuel used for main and auxiliary engines and boilers (IMO, 2019).

Much more strict regulations were issued on 1 January 2015, concerning the sulphur limit for fuel oil used by ships operating in Emission Control Areas (ECAs). The regulation designated by IMO sets the limit of sulphur oxides (SOX) in ECAs at $0.10 \% \mathrm{~m} / \mathrm{m}$. Among the ECAs established under MARPOL Annex VI for SOx in Europe there is Baltic Sea and North Sea with strict emission regulations supporting clean shipping - the SECA legislation, which requires that ships sailing in the Baltic and North Seas cannot use fuels with more than $0.10 \%$ Sulphur content (Boyesen, 2019). Complying with the SECA regulation allows to reduce emissions from ship engines, by providing appropriate kind of marine fuel for the respective engine technology, instead of using High Sulphur Fuel Oil (HSFO). Compliance with the emission limits can also be guaranteed with additional equipment (filter systems, scrubbers) (Marine Fuels, 2019). Moreover, it requires a change of bunkering models in marine ports. The ports are supposed to supply ships with a variety of new fuels, such as: 
- LNG (liquefied natural gas),

- MGO (low sulphur marine gasoil),

- ULSFO (Ultra-Low Sulphur Heavy Oil),

- methanol.

These are fuels of much higher quality parameters in terms of ignitibility (Calculated Carbon Aromaticity Index/CCAI), maximal acid and metal content, and sulphur content limits. Ships taking on fuel oil for use on board obtain a bunker delivery note, which states the sulphur content of the fuel oil supplied. Samples may be taken for verification.

Additionally, ships must be approved with an International Air Pollution Prevention (IAPP) Certificate by their Flag State. This certificate includes a section stating that the ship uses fuel oil with a sulphur content that does not exceed the applicable limit value as documented by bunker delivery notes or uses an approved equivalent arrangement (IMO, 2019).

\section{Main pollutants}

Ports are the source of a variety of environmental hazards. As a result of standard port operations, air quality in port areas is affected by various pollutants, of which the most significant are:

- visible dust, smoke and odours,

- inhalable and respirable dust,

- volatile organic compounds (VOCs),

- $\mathrm{NOx}, \mathrm{PM}_{1} 0, \mathrm{PM}_{2} \cdot 5, \mathrm{SO}_{2}, \mathrm{NOx}, \mathrm{CO}_{2}$,

- noise.

As dust and odours emissions are mostly related to the natural sources: the movement of vehicles inside a port initiates dust and odours usually due to the physical features of transshipped cargo, they can be a source of temporal irritation or respiratory problems for human bodies. They may adversely affect the quality of human life in the vicinity of a seaport, but are not considered to be a serious threat to human health and the environment.

Air emissions can be divided into two groups: Common Air Contaminants (CACs) and Greenhouse Gases (GHGs). Main CACs are: Oxides of nitrogen (NOx), oxides of sulphur (SOx), particulate matter (PM), among others. Combustion emissions from ships and other port and intermodal vehicles based on crude oil include mainly SOx, NOx, PM, CO and VOCs and they depend mainly on the used engine types and fuel properties. The amount of pollution emitted by vessels during manoeuvring, loading, unloading, and hotelling phases is $4.5 \%$ of $\mathrm{SO} 2$ and $6.2 \%$ of NOx of the total pollution emitted by the ships (Gariazzo et al., 2007, cited in Merk, 2010). 
GHGs are gases present in the earth's atmosphere that reduce the loss of heat into space. Main GHG gases are: Carbon dioxide (CO2), Methane (CH4) and Nitrous Oxide (N2O). GHGs affect climate as they concentrate in the Earth's atmosphere and trap heat by blocking some of the long-wave energy normally radiated back into space. Common air contaminants have a local or regional impact on air quality, whereas GHG pollutants have global impact on climate (Merk, 2010). Fuel consumption is the main source of these pollutants, and according to the Third IMO GHG Study (IMO, 2014) international shipping accounts for approximately $2.2 \%$ and $2.1 \%$ of global $\mathrm{CO} 2$ and $\mathrm{GHG}$ emissions on a $\mathrm{CO} 2$ equivalent $(\mathrm{CO} 2 \mathrm{e})$ basis, respectively. The emissions are not only related to transport shipping activity, but also to working engines when ships remain at berth, unless on-shore power supply is provided. Ships are also a source of refrigerant and air conditioning gas releases which account for the majority of HFC (Hydrofluorocarbons) emissions from ships. At container terminals also reefer container refrigerant emission has to be added to the amount of GHG generated in ports. Shipping-related emissions can represent up to half of the emissions of the port-city (Merk, 2010).

Among the air contaminants in ports, PM2,5 and NOx present higher externalities (Merk, 2010). Handling operations (loading/unloading) result in ambient PM concentrations in the form of re-suspension of mineral dust (road dust) (Viana et al., 2014). Particulate matter emissions are being reduced through the use of cleaner fuels with less Sulphur content. Current research evidences that shipping emissions may also enhance new particle formation in urban areas and thus contribute to other forms of air quality degradation (Viana et al., 2014).

Shipping emissions in ports are substantial, accounting for 18 million tonnes of $\mathrm{CO} 2$ emissions, 0.4 million tonnes of NOx, 0.2 million of SOx and 0.03 million tonnes of PM10 in 2011. Around $85 \%$ of emissions come from containerships and tankers. Containerships have short port stays, but high emissions during these stays (Merk, 2014). Shipping emissions have considerable external costs in ports: almost EUR 12 billion per year spent in 50 largest ports in the OECD for NOx, SOx and PM emissions, the emissions most directly relevant to local populations. Approximately 230 million people are directly exposed to the emissions in the top 100 world ports in terms of shipping emissions (Merk, 2014, p.10).

The largest part of emissions in ports is generally from shipping activity; this can be concluded from this collection of studies on emissions in ports. Between $70 \%$ to $100 \%$ of emissions in ports in developed countries can be attributed to shipping; trucks and locomotives represent up one fifth, whereas emissions from equipment rarely exceed 15\% (Merk, 2014). 


\section{Policy measures implemented in port areas}

Various policy measures implemented in ports to mitigate air emissions have been undertaken in European ports, such as the EU regulation concerning the use of low sulphur fuel at berth, shore power and various fuel switch programs. However it is not common for marine ports to establish a public Clean Air Policy document, which would identify policy goals and measures that have already been implemented, together with the presentation of measurement results. Some environmental port reports are detailed, whereas some are of a rather general character. There is no standard legal framework to set standards of Air Quality Control reporting in marine ports, therefore ports decide individually on their Air Quality Policy and data presented by ports are difficult to compare.

For example, in Deepwater Container Terminal in Gdansk, Poland, significant data sets have been collected concerning (DCT, 2016):

- overall energy consumption on a yearly basis,

- the energy consumption of cranes (STS - Ship To Shore Container Cranes),

- emissions resulting from gas heating (terminal buildings)

- overall fuel consumption (diesel oil),

- fuel consumption (diesel oil) by terminal vehicles and machinery,

- fuel consumption by RTG - Rubber Tyred Gantry Cranes.

Data available online are limited to 2015 and 2016.

Main emission sources have been identified as:

- combustion of diesel oil in engines of power generators of cranes,

- combustion of diesel fuel in engines of vehicles and machinery moving on storage yards,

- combustion of gas and fuel oil in boilers,

- combustion of gas in heaters,

- combustion of diesel fuel in vehicle engines in a garage of the maintenance department - exhaust extraction,

- fuel combustion in emergency generator engines,

- welding in the assembly room,

- battery charging,

- transshipment of diesel fuel at the service station.

The document sets the main environmental goals in 6 categories (mitigation of airborne emissions and improving energy performance as one of the categories) for DCT Gdańsk, and presents the procedure of identification and assessment of environmental risks, together with the tools to gather and analyse data on environmental risks resulting from all processes taking place inside the terminal. The analysis also includes entities acting as subcontractors, as long as the characteristics of their operations may be influenced by the port. The data 
concerning emissions are categorized and presented for basic pollutants $\left(\mathrm{NO}_{2}, \mathrm{CO}, \mathrm{CO}_{2}\right.$, aliphatic hydrocarbons and dust). Environmental goals in the field of airborne emissions reduction are identified and described as:

- electric RTG Cranes on Terminal II (deployed in 2016),

- electric railway cranes (not deployed until 2016, planned for deployment in 2018-2020),

- road vehicles class Euro 5 (deployed in 2016).

Described environmental policy applies for DCT Gdansk only, whereas Port of Gdańsk and Port Authority does not supply detailed information in terms of air pollution and emission control procedures.

Air Quality Policy portfolio may also include other measures, such as the use of eco-efficient diesel-powered reach stackers, cranes and horizontal transport equipment that can substantially reduce fuel consumption in comparison to traditionally powered equipment (e.g. Port of Kalmar). Additionally the use of shore power facilities in ports allows ships to shut off their auxiliary engine and use the power of the grid in the port to minimize their emissions (e.g. Ports of Gothenburg, Trelleborg, Luebeck). Promotion of LNG use in ports is another measure that can be undertaken. Some ports have decided to not only promote LNG as a ship fuel, but have also been offering ship services based on LNG (Bremenports). Another incentives for shipping lines may come in the form of lower port fees for ships which reduce speed in the vicinity of the port or switch to low sulphur fuel while in the port.

\section{Air Quality System Modelling}

To adopt an effective air quality policy it's necessary to measure the levels of pollutants generated exclusively on port area. Some European ports have already decided on measuring some of the emissions, for example, in the Port of Gothenburg direct emissions from operational vessels, operational vehicles, heating buildings (by fuel usage) and emissions from vessels at the quay and in port traffic area has been measured (Merk, 2014). The measuring system usually consists of data collection featuring the Common Air Contaminants (NOx, SOx, CO, VOCs, PM10, PM2.5, NH3, GHGs - $\mathrm{CO}_{2}, \mathrm{CH} 4, \mathrm{~N}_{2} \mathrm{O}$ ) and daily and monthly data analysis to show contamination level fluctuations. It is advisable to reach for the examples of measurement systems being used by ports in numerous countries that have been described in literature and use their experience to develop an effective air quality policy.

The next step is to evaluate the level of emissions by certain vehicle and vessel category and set limits and targets to be addressed by port's Clean Air Policy, either in relation to limits set in official regulations or in relation to inner goals, that can be set by ports individually. Environmental goals are usually set on the basis of Corporate Social Responsibility Policy of the port, as a result of social consultations with stakeholders, especially local residents. 
They may result from local geographic conditions (topography of the land), specification of the port main activities, features of the transshipped cargo, surrounding urban area requirements or other CSR activities the port is involved in. However, in every case, individual goals must comply with limits set in official regulations applicable in the region.

When the goals are set, the tools and measures need to be planned. In this phase of policy building it is necessary to describe processes and actions that need to be taken in order to control and mitigate emission levels. It is necessary to set KPIs (Key Performance Indicators) for each goal, that will allow to estimate to what extent the goal has been achieved in assigned period of time.

After the planning phase, the processes are enabled and data collection continues, however at this point incoming data concerning emissions, energy consumption, noise and other pollutants identified are also structured according to various categories that illustrate the characteristics of airborne pollution and will allow for KPIs to be calculated.

Since emissions of hazardous substances occur due to the activity of certain groups of equipment and infrastructure, it is a primary concern to identify the sources of emissions, describe their impact (level of emissions) combined with their activity profile. Literature review undertaken by Merk O. (2014) shows that there are two main approaches to the method of emission calculation: based on fuel consumption and activity-based. In the firs method, fuel consumption by a vehicles and vessels is measured in a certain period of time. The calculation is done for every type of vehicle and vessel operating in the port. In the latter method, activity time or activity profile of a vehicle or vessel is specified. For example, the activity of a ship is divided into the hours spent cruising, manoeuvring and hoteling, whereas the first approach consists in looking at fuel accounts of ships to estimate emissions. This approach also requires further identification of a vehicle/ship type (containerships, tankers, bulk carriers, ro-ro, inland barges or port vessels such as tugs). Transport vehicles within the port such as port trucks, locomotives, and cargo handling equipment, such as cranes and other equipment, need to be included in the calculation.

The calculations' results should be divided into categories with respect to geographical area (port area and territorial waters), which makes it easier do see where certain emission levels occur, and can be an advantage when comparison of emission levels between different ports is needed.

The data are collected for assigned period of time. A year perspective is most convenient for data comparisons describing the effects of undertaken environmental measures. In this phase a report is created, based on collected data, presenting the measures together with their effects and with KPIs supplying the necessary data. It is then possible to decide which goals have been reached and to what extent the policy has been effective. On the basis of data analysis goals can be modified or set anew. It is also possible that some processes, especially those that require costly and time-consuming investments, will be assigned for control over a period of time 
exceeding one year. This may be the case of complex infrastructural projects, for example supplying LNG facilities in a port.

These steps need to be followed in a circular sequence for another year, providing the port with an effective Air Quality Control Model. This approach is based on PDCA cycle, also known as the Deming Cycle, which is a planning and implementation tool often used in management processes. It places business processes in continuous feedback loop, which allows for optimization of the processes. It divides processes into phases called PLAN, DO, CHECK and ACT (Moen, 2010). Air Quality Control process can be standardized in the form of PDCA cycle (Table 1).

The general structure of the model can be used to implement Air Quality Policy in marine ports, as well as in inland shipping ports. The models will differ due to the size of the port and port operations volume and characteristics. However, environmental goals and KPIs to identify the effectiveness of assigned policy can be developed based on experiences and models already implemented in other ports of the region.

\section{Table 1.}

Air Quality Control Model based on PDCA Cycle

\begin{tabular}{|c|c|}
\hline PDCA phase & Air Quality Control Process \\
\hline $\begin{array}{l}\text { PLAN (determine goals and } \\
\text { methods of reaching goals) }\end{array}$ & $\begin{array}{l}\text { - Identify sources of emission, } \\
\text { - Measure the level of pollutants in the port area, } \\
\text { - Set limits of airborne emissions for each emission source, } \\
\text { - Set other environmental targets, e.g. concerning noise pollution or } \\
\text { odours mitigation, } \\
\text { - Plan tools and measures to be taken, } \\
\text { - Plan Key Performance Indicators for each goal, }\end{array}$ \\
\hline DO (Implement work, educate) & $\begin{array}{l}\text { - } \\
\text { - } \quad \text { Data collection and structuring, } \\
\text { - } \quad \text { Emission calculations for assigned categories, }\end{array}$ \\
\hline $\begin{array}{l}\text { CHECK (the effects of } \\
\text { implementation) }\end{array}$ & $\begin{array}{l}\text { - } \quad \text { Calculation of KPIs, } \\
\text { - } \quad \text { Data comparison (planned vs achieved), } \\
\text { - } \quad \text { Assessment of processes' effectiveness, } \\
\text { - } \quad \text { Optimization of goals and procedures, } \\
\text { - Setting new goals, }\end{array}$ \\
\hline ACT (take appropriate action) & $\begin{array}{l}\text { - } \quad \text { Drawing conclusions, } \\
\text { - Learn from the experience, } \\
\text { - } \quad \text { Accumulate knowledge, } \\
\text { - } \quad \text { Prepare data to optimize processes, } \\
\text { - } \quad \text { Start the new processes' cycle. }\end{array}$ \\
\hline
\end{tabular}

Source: own elaboration based on (Moen).

Most shipping emissions in ports $(\mathrm{CH} 4, \mathrm{CO}, \mathrm{CO} 2$ and $\mathrm{NOx})$ are estimated to grow fourfold up to 2050. This would bring CO2 emissions from ships in ports to approximately 70 million tonnes in 2050 and NOx emissions up to 1.3 million tonnes (Merk O., 2014) which results in the need to address the issues in ports' strategies to a much larger extent in the future. 


\section{Conclusions and discussion}

There is a link between air quality in ports and energy consumption models in maritime sector which is simple to calculate using shipping and port-machinery emissions per work-hour. Ships and other vehicles calling to ports using diesel engines generate most of the emissions. Alternative low-sulphur fuels or other eco-friendly energy sources such as LNG, biogas, or solar power may contribute to airborne pollution mitigation in ports in the long run, however current predictions indicate that port emissions, especially those generated by ships, will be rising. As a result, it becomes important for more ports to establish an effective airborne pollution mitigation system. However, there's still no business value for the ports to establish a precise emission control system and collect and publish the data. It has rather been the case of Corporate Social Responsibility strategy than a business interest. Therefore there is a need for more international regulations in this respect. In Europe, ports located in densely populated and urban areas will be facing the need to communicate with local communities in terms of generated airborne pollution, its effects and measures to mitigate the environmental pressure of port areas. A comprehensive and efficient Clean Air Policy model implementation may turn out to be the key of the communication with all stakeholders.

Among the basic possible difficulties in establishing the model, the problem of accurate measurement of emissions of harmful substances from different sources can be mentioned. Port emissions are in most cases blended with urban emissions, which makes it impossible to assess the volume of emission occurring solely on the port area. Moreover, ports are located in windy areas, making measurements even more difficult. Therefore the methods mentioned in the article present a way to address these difficulties.

It is also important to note that air quality control is one of numerous environmental issues addressed by ports worldwide, such as waste management, water pollution and preservation of biodiversity in port area among others.

\section{References}

1. Boyesen, J. (2019). Impacts from clean shipping for Port Cities-Report from four EnviSuM workshops. Available at: mdc.center/envisum.

2. DCT Gdańsk, Deklaracja Środowiskowa za 2016 rok. Available online: dctgdansk.pl/wpcontent/uploads/2014/04/20170614-Deklaracja-środowiskowa-2016-podpisana.pdf, 15.06.2019.

3. ESPO ENVIRONMENTAL REPORT 2018, EcoPortsinSights 2018. Available online: https://www.espo.be/media/ESPO\%20Environmental\%20Report\%202018.pdf. 
4. Marine Fuels. Available online https://www.marquard-bahls.com/en/news-info/glossary/ detail/term/marine-fuels.html, 16.06.2019.

5. Merk, O. (2010). The Competitiveness of Global Port-Cities: Synthesis Report. Available at: www.oecd.org/regional/portcities, 15.06.2019.

6. Moen, R. Foundation and History of the PDSA Cycle. Retrieved from https://deming.org/uploads/paper/PDSA_History_Ron_Moen.pdf, 15.06.2019.

7. NABU, Clean Air in Ports. EU-LIFE+ Project "Clean Air". 2015. Available online https://en.nabu.de/imperia/md/content/nabude/verkehr/cleanair/150529-nabucleanair_manual.pdf.

8. The 2020 Global Sulphur Limit. Available online www.imo.org/en/MediaCentre/ HotTopics/GHG/Documents/2020\%20sulphur\%20limit\%20FAQ\%202019.pdf, 16.06.2019.

9. Third IMO GHG Study 2014. Available online: www.imo.org/en/OurWork/Environment/ PollutionPrevention/AirPollution/Pages/Greenhouse-Gas-Studies-2014.aspx, 15.06.2019.

10. Viana M., Hammingh P., Colette A., Querola X., Degraeuwe B., De Vlieger I., Van Aardenne J. (2014). Impact of maritime transport emissions on coastal air quality in Europe. Atmospheric Environment, Vol. 90, pp. 96-105. Retrieved from https://www.sciencedirect.com/science/article/pii/S1352231014002313,.06.2019. 